Reports in Advances of Physical Sciences

Vol. 1, No. 1 (2017) 1750001 (27 pages)

(C) The Author(s)

DOI: $10.1142 /$ S2424942417500013

\title{
From the Physiocrats to Fairness in Nations
}

\author{
Yekbun Adigüzel \\ Istanbul Kemerburgaz University \\ Bakirkoy, Istanbul, Turkey \\ yekbun.adiguzel@kemerburgaz.edu.tr \\ Ophir Flomenbom ${ }^{* \dagger}$ \\ Flomenbom-BPS Ltd, 19 Louis Marshal \\ Tel Aviv 62668, Israel \\ ophir1974@flomenbom.net \\ Gul Unal Coban \\ DokuzEylul University, Buca/Izmir, Turkey \\ gulunalcoban@gmail.com \\ Received 27 July 2016 \\ Revised 27 September 2016 \\ Published 30 December 2016
}

\begin{abstract}
In this review, work from three centuries of biophysical economics is presented, starting from the physiocrats' early work in biophysical economics in 1755 , to the most recent modeling of modern societies with approaches from biophysics and physics, to explain the wealth distribution, opinions and power structures in societies and nations. At the same time, we are also dealing with generalizations, in particular, how to define and create fairness in nations. The general conclusions emphasize the strength of socio-econo-physics in explaining nations, also in comparison to the other approaches, due to the unbiased starting points and diversity in methods. The results emphasize that fairness is increased with citizens' activities that create smoother income distributions and improving the flow of opportunities in the nation. Fairness also fights unjust socio-economic biases and suggests advancing citizens-managed organizations.
\end{abstract}

Keywords: Socio-physics; econo-physics; socio-econo-physics; biophysical economics; economic biophysics; physics of society; physiocrats; fairness in nations.

*Chief Editor in this Special Issue.

$\dagger$ Flomenbom-BPS Ltd is a private scientific company.

This is an Open Access article published by World Scientific Publishing Company. It is distributed under the terms of the Creative Commons Attribution 4.0 (CC-BY) License. Further distribution of this work is permitted, provided the original work is properly cited. 


\section{Introduction}

\subsection{The goal in this review}

The goal of this work is to present the biophysical economics' strength to explain and to improve nations, together with a brief historical presentation of the subject. The biophysical economics approach to the economic aspects and dynamical models of society is focused on evaluating and formulating the resources, and their dynamics, with terms and approaches from the area of biophysics, like applying thermodynamics to the resources' scarcity problem, and mathematical biology, like the adaptation of the Lotka-Volterra's prey-predator dynamics to the societal modeling. We start with a historical presentation about the physiocrats' work from 1755 , involving agriculture-based energetic computations ${ }^{1}$ to explain societies, and then presenting the basic concepts in biophysical economics. We continue to the more general energetic computation approaches, and then to the advanced methods and approaches of socio-econo-physics of today. ${ }^{2,3}$ Upon utilizing the advanced methods, we then define the meaning of, "fairness in nations", compute it, and finally analyze the question, "how do we advance fairness?"

\subsection{Basic concepts in biophysical economics}

Biophysical economics gives us the possibility of explaining the society with approaches and methods from biophysics and mathematical biology, physics and interdisciplinary physics. ${ }^{2,3}$ These can complement the current approaches of economics and social modeling. This multidisciplinary area is defined today by the various variants of inter-related terms, each emphasizing a particular side of the whole area, e.g., socio-physics, econo-physics, socio-econo-physics, physics of societies, mathematical-economic-biophysics, and biophysical economics, to name the most common ones. However, the sub-areas represented by these terms cannot be distinctly separated, therefore they share many common terms and can be used interchangeably quite often. That ensemble of approaches in this multidisciplinary area of biophysical economics might explain today's nations better than the "closed box concept" of economics.

Perhaps the earliest scientific involvement of biology in economics as a discipline is in explaining the possible economic progress in societies with the energy generated from agriculture. ${ }^{1}$ Dealing with energy, including its forms, its transformations, its storage and transportation, and eventually its generation rate, has contributed the most in the early stages in the field of biophysical economics within the 1700s. Still, the view of people about economics is much more basic and is connected with wealth, knowledge, and survival. Wealth is the abundance of the valuable material that is being possessed. The term "valuable" could be relative but in the simplest sense, wealth could be defined with just simple belongings and "hierarchal control on the others". At earlier times of civilization, belongings were the possession of or access to the food, stock, water, and house, which were not as varied as today. In the past, the 
source of wealth accumulation was mainly based on agriculture, which could be owned directly such as the land, and laborers, and livestock. The process of wealth accumulation and man's lifestyle has altered dramatically over the years since the 1700s. Tools were invented; clocking system was developed, enabled the regulation of daily working hours to get the most out of daylight; also eating habits changed, and resulted in a cognitive development. ${ }^{4}$ In time, accumulation of goods, arts, and knowledge occurred, generating the manufacturing periods and the evolution of distinct economic systems. We can emphasize that the 1600s and 1700s generated many basic advancements in science, technology, sociology, and economics, and created the era of an inclined economic growth rate, relative to that of the previous. These also affected the governance manners and generated the atmosphere where modern cities evolved. There, energy flow was characterizing and still characterizes people's lives and economies. Energy flow can slow down but at the same time it is continuous, unending, and not limited to the life cycles. Its flow is directional and favors degradation of material when energy is released and absorbed by the surrounding medium. Nevertheless, it is also cyclic, in the sense that there are diverse processes that involve energy flow in any direction together with material organization, disorganization, or reorganization. When the scarcity of resources and energy is mentioned here, which was dealt tremendously by the pioneering scholars of the biophysical economics, such processes that form controllable, high energy releasing form of materials, namely fuels, are mainly involved. The fossil fuel consumption is an example of the circular flow of matter and energy. These descriptions appeared quite early in the physiocrats' work.

Man's goal is to make the most of energy release from the fuel and generalizations and harness it for vast number of needs. The conflict is that the resources are limited. (Except for the radiation that is reaching on the ground from the Sun yet this is more noticeable today due to the technological advances in harnessing that energy.) There are also other problematic issues with energy generation, such as the requirement of proper waste elimination and the possible hazards from nuclear plants.

The resources are not limited only to the energy resources but it is the most widely discussed subject in terms of economic activities, so it appears on top. However, when resources' scarcity is mentioned, one could mean any resources' type.

\subsection{On the review structure}

Following the brief introduction above, a brief historical perspective is presented, and the advanced approaches in the area of socio-econo-physics are reviewed then, where the influences of biophysical economics in the scientific community are also referred in that section. Sections 4 and 5 are focused respectively on the definition of fairness from the sociological sides and the presentation of the mathematical modeling of fairness, through the examples of the "society-deciders model" and the model of the income density function and the Gini of fairness. Section 6 is the conclusion. 


\section{The Biophysical Economics' Historical Presentation}

The roots of biophysical economics can be attributed to the physiocrats, with the pioneering works of Francois Quesnay and the others in that group (Fig. 1). ${ }^{1,5}$ In those years, Industrial Revolution was yet to occur and agriculture was the main occupation in the society. Most material wealth was credited to the fertile lands and the workforce. Cities had already been established and were demanding other types of workforces, comprised of mainly intellectuals, scientists, inventors, etc. Promotion of the systematic knowledge transfer and scientists' work and efforts resulted in the initiation of a deeper understanding of the Laws of Nature and their impact on the social systems. The recognition of the Laws of Thermodynamics, ${ }^{6,7}$ thanks to the scientists like Joule, Clausius, William Thomson Kelvin, Maxwell, and Boltzmann, brought about the Industrial Revolution and progress by that period. Invention of the steam engine, explained by Carnot in 1824, was the technological advancement at the roots of this revolution. ${ }^{8}$ Recognition of the potential impact of these discoveries in revolutionizing our lives and societies was likely the motivation that directed the attention of scholars in developing such technologies or doing such research. Also, mere observation of the society revealed the parallelization of its dynamics with those of the Nature, in terms of the organisms' endless fight for the scarce resources and energy, for the sake of survival. For instance, Spencer ${ }^{9}$ suggested that both biological and social processes reveal a characteristic ceaseless struggle for energy and resources. Podolinsky pointed that it is ecological and physical laws, not economic relations, that defines the limits of economic growth. ${ }^{10}$ Ostwald stated that civilization is just control on energy and that control roots all the transformations around us. ${ }^{11}$ It could be the case in a distinct perspective although seeming at first glance as a mere simplification of all the complex processes that involve immense cognitive work at the engineering side ultimately as a form of energy control. Yet, we believe that such understandings were critical in the sense that they paved the way to the forthcoming energy oriented analyses. Energy flow analysis emerged as an important theme in this area. ${ }^{12-19}$

The 20th Century witnessed a net recognition of the transforming role of the type of resources we use for energy extraction. Soddy put forth the influence (on the

Industrial

Revolution

Advanced thermodynamics

$$
\text { Radiation \& electricity }
$$

Physiocrats

Thermodynamics

Computers Advanced biophysical economics

\begin{tabular}{lllllllllllllrrr}
\multicolumn{1}{c}{ Thermodynamics } & WW1 & WW2 & Information & & physics $\begin{array}{r}\text { physics of } \\
\text { societies }\end{array}$ \\
1755 & 1800 & 1840 & 1880 & 1900 & 1915 & 1939 & 1945 & 1959 & 1969 & 1970 & 1990 & 2010 \\
\hline$\# 1$ & $\# 2$ & $\# 3$ & $\# 4$ & $\# 5$ & $\# 9,10,11,12$ & $\# 13,14$ & $\# 13$ & $\# 14$ & $\# 15$ & $\# 16$
\end{tabular}

Fig. 1. Illustration of biophysical economics' advances, with the developments in science and technology, where the lower panel of numbers refer to the conceptual highlights and the respective scholars that are presented in the Table 1. 
boosted economic growth) of changing from what was defined then solar energy, namely agriculture-oriented economic growth concept, to the fuel energy. So, other forms of energy resources appeared in the processing and production of goods, and this meant additional economic activities with a significant input value. In accordance, analogous with the custom understanding, Soddy made the resemblance between fossil fuels and capital, and solar energy and revenue, wherein fossil-fuelsbased growth is like that from capital yet solar energy was the driving force of agriculture as a constant, regular income. ${ }^{20,21}$ Soddy then argued against the standard economic approaches and the contradiction between the debt with speculative nature and welfare with non-speculative background. Criticism of the classical theories was common in biophysical economics. This is understandable since there were some weaknesses of the classical approaches but the critical approach was also due to the need to convince the community, to make the necessary alterations or shifts in the paradigms of the day. Without a direct economic relation, Lotka presented a relevant evolutionary perspective with energy at the center of natural selection, that can result in the survival or extinction of organisms. ${ }^{22,23}$

The Technocrats, pioneered by Scott and collogues, argued to the replacement of money with energy certificates, and politicians with engineers and scientists. ${ }^{24}$ However, World War II began soon and this view could not find the grounds for further dissemination. The 20th Century was also underpinned by the energy quality concept, together with the social and economic aspects, and the accumulation of scientific work and data. ${ }^{25-30}$ For instance, a geophysicist Hubbert was gathering data on the energy production, discovery, and consumption rates. ${ }^{31-34}$ Similar to the earlier views of Podolinsky, ${ }^{10}$ Cottrell was emphasizing the surplus energy, wherein technological advancements created more efficient energy extraction from fossil fuels. ${ }^{16}$ Energy quantity was not limiting the productivity any more. Accordingly, he also emphasized the labor productivity per unit quantity of energy. In relation to the assessments of Soddy, Cottrell mentioned the transforming effect of Industrial Revolution gained by supplementing the workforces with excessive energy. However, the time-dependent change in the energy surplus amount has economic consequences. This fact is based on two parameters, means of energy extraction and physical properties of the resource, as the main limiting factor of the energy content of the resource in question. Cotrell's views had commons with those of Lotka's and Spencer's, suggesting the dependence of our survival success on controlling the energy conversions. Control on the energy transformations means better energy transformations with higher yields, and the computation of the efficiency in these transformation amounts and types. In relation, Odum pointed at the requirement of consuming energy with an optimum rate and matching the energy that is in use for the economic task in question. ${ }^{17}$ This was termed by Odum as "maximum power principle." It was advancing the previous evolutionary perspectives of the maximization of energy for survival. Odum contributed to the field also with the counter flow concept, wherein economy is the response system for supplementing money and energy to the purchase sites, for production of more of those goods. A supporter of 
Odum was Costanza, who established that the embodied energy and dollar value of goods were statistically related. ${ }^{35,36}$ Embodied energy is the entire energy content of a good that includes all types of energy that is spent on the production of a good from its raw materials, including that for obtaining the raw material. Costanza suggested that the relation between the embodied energy and dollar value of goods can be used for valorization of the goods and nonmarket externalities. In those days, Cook pointed at the potential hazards and ecological concerns, and offered to take precautions. ${ }^{37,38}$ Hannon had such concerns as well and suggested establishing an energy conservation ethic, in addition to the use of energy coupons in place of money. ${ }^{39,40} \mathrm{As}$ a result, understanding (non-renewable) energy as an important facet of economics led to the recognition of ecological aspects of the accelerated energy consumption and waste production cycles during the manufacturing or service processes.

Ayres established the material-energy balance model. ${ }^{41-44}$ With thermodynamics terms, he described the high quality resources as the high-quality negentropy stocks that are easy to find and extract, and founded the term "exergy" to define the organization degrees of matters in low entropy states, compared that in their high entropy states. These discussions were based on the fact that our civilizations run on the non-renewable energy and material sources on Earth, meaning that their consumption will deteriorate the available amount, and the pollution that is generated will have further adverse effects. Daly offered to try managing a steady-state economy through keeping the population and resources constant, under control. ${ }^{45,46}$ Georgescu-Roegen objected this view due to the resources' limitation. ${ }^{47,48}$ Namely, the resources would then still be consumed but at a constant rate rather than an increased rate, proportional with the population-size. Georgescu-Roegen also formulated the 4 th Law of Thermodynamics, dealing with the organizational state of matter. ${ }^{49}$ So, the recent 21 st Century approaches in biophysical economics focused on analyses and establishing mathematical models. ${ }^{50-65}$

More recently, with regard to the information oriented lifestyles of today, Szilard argued about the interdependence of information, time, and energy, and their

Table 1. List of the scholars (mentioned in Sec. 2) and their selected contributions and views.

1-) Physiocrats; Quesnay \& his disciplines:

$>$ Carried natural resources to the center of the first disciplined economic thought school

4-) Soddy:

$>$ Transition from solar energy to fossil fuels

$>$ Transition from revenuebased to capital empowered growth

- Speculative background of debt vs solid nature of wealth
2-) Ostwald:

$>$ Civilization $=$ control on energy

5-) Lotka:

* Energy (maximization) is at the center of survival (natural selection)
3-) Podolinsky:

$>$ Economic growth limits are in the physical and ecological laws rather than production relations

- Energy flow analysis

6-) Scott:

$>$ Technocrats: suggesting replacement of politicians with engineers and scientists,

$\checkmark$ money with energy certificates 
Table 1. (Continued)

\section{7-) Cottrell:}

Surplus energy \& time-dependent change within, related mainly to the physical properties of resource \& then to the technique of its extraction

Labor productivity in relation to energy quantity

$>$ Increase in revenue-based systems' efficiency

* Man-survival relies on success of control on energy transformations

10-) Odum:

- Systematic energy flow analysis

- Counter flow of money and energy; money production has speculative but energy has solid nature

> "Maximum power principle" is energy maximization to be used in useful work to survive

\section{3-) Hannon \& Energy Research Group:}

Suggested establishing energy conservation ethic

$\checkmark$ Energy coupons

\section{1-) Costanza:}

8-) Spencer:

Social and biological evolutionary processes are the struggle for energy and resources

* Evolution: Continuous dissipation of energy and integration of matter as a more coherent form, which survived

\section{9-) Hubbert:}

$>$ Geophysicist, gathered data on energy production, discovery, consumption rates

- Argued on speculative side of economics

\section{4-) Ayres:}

- Material-energy balance model

$>$ Standard economics is incompatible with the First Law of Thermodynamics

Described resource quality as high-quality "negentropy" stocks

- Coined "energy" term as measure of energy quality through materials' organization degree at low entropy state compared to that in high entropy state
12-) Cook:

$>$ Concerned with the exhaustion of resources and associated environmental threat, together with blind belief in economic regulations and technological advance

$>$ Suggested precautions like adjusting lifestyles

15-) Daly:

$>$ Argued on classical economics due circular flow concept, which is expelling natural resources \& wastes

$>$ Suggested steady state economy model, keeping resources \& population constant (Georgescu-Roegen criticized this since material supply cannot be kept constant)

\section{6-) Georgescu-Roegen:}

suggested the 4th Law of Thermodynamics or Law of Matter

- Entropy, dealing with degradation of the organizational state of matter

">" sign indicates separate distinct highlights on the views of the selected scholars.

"ø" stands for the common concept about "energy flow".

"o" shows the shared critical view on the classical economic theories.

" points at the evolutionary perspectives.

" $\checkmark$ " indicates the opinion of implementing alternatives like energy coupons or energy certificates instead of money.

"口" specifies the energy-balance model, which is related to the embodied energy concept.

"•" is used to point at the common interest of on the organization degree of materials with respect to their energetic contents and entropies. 
vitality in our lives and economic systems. ${ }^{66-70}$ Information always had a foremost place in our activities. Information revolution is shedding light on many matters, ${ }^{71,72}$ and becoming more influential with the advanced communication technologies.

\section{Advanced Approaches and Results from Socio-Econo-Physics}

\subsection{Beyond basic energy computations' approaches}

In an opinion article from 2013, The Economist argued that writers like Turgot, Condorcet, and Quesnay are not commonly heard even by the well-educated people, yet the physiocrats, the group that those were the members of, created the first scientific system of economics. ${ }^{73}$ The claim of the article was that it is the physiocrats' contribution to methodological approaches that made them valuable. Yet we especially give credit to this simplistic approach indeed since it is revealing the intrinsic connection of economics with the limited Natural resources in the form of (productive) lands. It is interesting for the biophysical economics' perspective that Quesnay was also a scientist, a medical doctor, and he wanted to treat the economy like a human body, with a respectful and analytical approach rather than treating it as a mold that should fit to the selfish wills of monarchs. This view is sound and could be appreciated better by considering the inherent relation of the energy-dependent nature of the body and its associated pathological conditions. One can easily argue that economics is only part of our systems that exist to serve us; therefore it can be manipulated and shaped to fit our desires. However, such views are not far from the understandings of those people who behave carelessly end with pathological states and physical failures. Yet such analogies are just general. Still, wealth of a nation could be regarded as analogous to the health of a body, where the definitions of wealth and health and the states that they refer to changed much pronouncedly in case of wealth. The nation's wealth definition is more general than that defined in the 1750s. Besides, there is wealth accumulation in the top $1 \%$ of the nation but increasing the overall wealth (health) requires the treatment of the whole nation (body). There are also matters like the ecological status and quality of the environment, where the nation exists, and influence the nation's wealth in turn.

The evolution and advancement in the scientific discipline of biophysical economics starting from the 1750s was the result of the changing societies and environments, especially the cities, which were becoming more and more (energy) demanding, larger, crowded, and cosmopolite. The energetic computations and balances changed during the following three centuries, from agriculture based society to the Industrial Revolution (starting from 1770s), and during the foundation of the very populated cities ${ }^{74}$ with their increasing needs and ecological issues. The energy that is consumed through the agriculture and associated sectors, including the energy that is utilized by the crops during their growth periods, probably would still be making the highest portion of the total amount of the energy that is consumed. However, people do not bother about agriculture except for the diminishing sizes of 
the lands that are spared for farming due to ever increasing population. So, agriculture is still correlated with the ultimate wealth of the nations, yet matters that determine wealth became numerous and diversified.

In particular, means of production changed and the processes advanced with the Industrial Revolution, in conjunction with the types of human acts. Further, all were realized together with the establishment of the sophisticated cities, ${ }^{74}$ with numerous and varied necessities, involving the transportation, communication services, and wider distribution networks for the delivery of foods and elimination of wastes, wherein ecological issues were thus recognized. So, both environment and health concerns were raised in an interdependent fashion. These were the issues to cope with due to the industrialization-driven progress and the resulting wealth. These were needed soon to be treated along with the problems as the resources' depletion and diminishing quality of the energy stocks, in terms of their embodied energies.

Resources (at least the high quality ones) and generalizations, e.g., quality information and knowledge, are scarce. Besides, maintaining large stocks of material and resources at densely-populated regions are generally more expensive than maintaining the same amounts as smaller portions since extra expenses come along with the increasing sizes to be managed. For instance, sanitation is a major concern when water and raw food have to be stored in large quantities for long term periods. ${ }^{75}$ (Similar statements are valid also when we deal with generalizations, e.g., information.)

Today there are many other issues to deal with due to the globalization, computerization and the internet, or the automated production. At least, all of these influence economies. The flow of information matters, where part of the treatment involves just the generalizations of the "resources" modeling reviewed above. Yet, other matters are unique to our era (these recent 20, 30 years), e.g., the speed of information flow is the fastest of ever due to the internet and the other communication technologies and this affects the entire economy.

The influence of biophysical economics and socio-econo-physics in the scientific economic community and policy makers depend on their abilities to better performance in the analysis of states, and predictions of the economic crises, solutions, etc. We can argue that biophysical economics and socio-econo-physics approaches already proved to perform better than that classical economic models that failed to predict the economic crises, such as that occurred in $2007,2008,2009 .^{76-81}$

\subsection{Socio-econo-physical approaches}

Until here, we presented the historical development of energy-oriented biophysical economics, partly with ecological treatments. We will proceed by giving worthy examples from the recent socio-econo-physical approaches that emerged recently as a relatively distinct perspective in the biophysical economics. In relation, the LotkaVoltera model in ecology ${ }^{82-85}$ is of great value in biophysical economics. ${ }^{76,77}$ We will provide relevant examples. The model is viewed among the most significant models from mathematical biology to appear in socio-econo-physics. The LotkaVolterra 
model is about the dynamics of interacting prey and predator populations' sizes. The model has various possible steady state results (fluctuations or extinction, i.e., if the predators eat too many from the prey population, predators get extinct) depending on the coefficients. Modeling more complex types of structures and interactions would reveal wider ranges of possibilities in the model. ${ }^{86,87}$

Many variants of the LotkaVolterra model exist in the biophysical economics and socio-econo-physics, like in case of the "society-deciders model" 76 that is utilizing the LotkaVolterra model with generalizations, with the aim of elucidating the effect of the interactions and structures on the states of our current societies. In the societydeciders model, the "99\%" circle and the top " $1 \%$ " circle of the society are the two major entities. Such a structure is reported in the literature, ${ }^{78,79}$ lacking proper modeling though. Reference 76 that will be mentioned more in detail in section 5 suggests that the nation is not fair if the condition of the "99\%" circle of the society is extreme, while the top " $1 \%$ " circle is stable, simultaneously.

To emphasize few more examples, ${ }^{80,81,88-118}$ models in socio-econo-physics and advanced biophysical economics can deal with the flow of opinions in the society, ${ }^{88-90}$ the citizens' work place flow, ${ }^{91,92}$ the flow of income and wealth in the society, ${ }^{91-106}$ structures of the societies, ${ }^{80,81,107}$ and forecasts of elections and opinions according to the sociological patterns. ${ }^{109-113}$ The historical evolution of biophysical economics $^{2,5-70,119,120}$ is important in understanding the dissemination and diverging of the area, becoming applicable to the analysis of the societies' dynamics, e.g., to the models and theories from sociology about fairness in societies. ${ }^{78,79}$ These are among the themes that are complementing the discussion about the nations' economies.

Within the area of biophysical economics, more recent works are remodeling the growth theory with biophysical economics or explaining growth with biophysical terms. ${ }^{50,121,122}$ These works are in conjunction with our state of understanding in societies and economics, wherein the changes in societies are represented in the economies, environment, science, and the production and consumption cycles. They reveal that all should meet to manage the consistent welfare, both for the nations and the World. People make the societies and their changes are represented in the economies since economy is based on the acts of people and their changes; therefore, transformations in the societies are represented in the economies and vice versa, e.g., the technology-driven impulses in the economies transform the societies. Biophysical economics and socio-econo-physics may do better in analyzing and understanding both the societies and the economies in deep, in a manner that is not limited yet nourished by the idea that "society is a collective system that depends on the resources in nature". Citizens are the units of the societies. Hence, we are also dealing with the citizens' drives, sensitivities, perception, acts, and aims to do "better than the others" (the competition drive), as individuals, or in groups. The acts of individuals and the responses of their environment then, together with the present power structures and the forces acting on those to reshape them, define the peoples' condition and the stability of the nation in turn. 


\subsection{Impact of biophysical economics in the scientific community}

The under-performance of the classical models in economics is primarily attributed to biased or erroneous assumptions. ${ }^{80}$ The subjective character of the traditional models would normally fail to predict economic crises. Yet, biophysical economics and socio-econo-physics work with more general starting points and in that sense can come up with more objective assumptions that have higher chances to predict shortages, crises, and the means to overcome those. Yet, they could also work with complementary tools better, e.g., with the existing sociological models, theories, and even surveys' results since these can be implemented better to the models. ${ }^{123,124}$ Hence biophysical economics have more flexibility and diverse tools to work with relative to the standard economic models.

Generalizations of the classical economic models (e.g., "game theory") are better derived in conjunction with the area of socio-econo-physics. Therefore, performances of biophysical economics and socio-econo-physics in modeling and explaining the diversity in nations would expectedly work better to solve the economic problems of today and help us to define fairer societies. One can work through problems that involve economic crises and therefore ask: Where do the crises emerge? When do they appear? How do they develop? How can we estimate or detect the signs of crises? How can we treat the crises conditions? How can we solve the problems that cause crises? How can we transform our systems into sustainable ones? Do we really need system changes or is there any means to manage sustainability with simple modifications in our current systems?

Yet we could pose a distinctive question involving fairness in nations. These and the other issues make the socio-econo-physics and biophysical economics worthy areas of research. We think that these would be reflected more in the scientific world and beyond, politics and the streets.

\section{How to Define Fairness?}

\subsection{Science education approaches to fairness}

Information and knowledge probably generate or at least influence the activities and therefore can improve them and give an impulse to do better and progress. This is critical and necessary to the development of both the individuals and the societies. In this sense, scientific knowledge has elemental role in the gross movements and changes in the society towards the enlightenment. ${ }^{125}$ The scientific knowledge infuses the societies easily if there are economic benefits, prospects, and no counteracting force, based on the fights over the control. The society can have a propensity for the readily uptake of the knowledge, wherein the rate of absorption (i.e., internalization) of the discoveries depend on the society. Differences in the social and cultural codes cause this difference. There is also the scientific critique. Although science is customarily defined as certain, unquestionable, and authoritative, this is rarely the case in science. Distinct from the traditional definition, science is defined by the 
constructivist epistemology as a theory laden act that relies heavily on the hypotheses and observations that are accepted by the scientific community. Therefore, scientific knowledge is told to be built collaboratively and is ever underprogress. ${ }^{126,127}$ Aikenhead $^{128}$ suggested that cultural values and the environment should be taken into consideration, in addition to the tenets attributed to the science and the scientific knowledge (as two inter-related processes), in order to be able to capture the essence of connections in between and dynamics within science, technology, society, and economy.

Beyond these discussions, perceptions are under the influence of our current environment and past experiences, namely the history, and have biological roots. So, attitudes and behaviors, and choices are not always straightforward outcomes of rational cognitive processes. The scholar view tells us that the core elements of these personal views rely on our conceptualization, the epistemology side, rather than what they really are, on the ontology side. Consequently, Thomas and Durant ${ }^{129}$ proposed 9 arguments for endorsing the awareness of science in public, which are the benefits to the public (1), national economics (2), national power and influence (3), individuals (4), democratic government (5), and the society (6), in addition to the intellectual (7), aesthetic (8), and moral (9) benefits. Personal attitudes to each will differ but the essence, which is the scientific literacy, is highlighting the prominence of some critical basic knowledge and skills of science and technology, such as skepticism, rationalism, objectivity, reliance on testability, etc., that can still hold inter-personal distinctions. Particularly, these attitudes need to be possessed throughout the lives. Perceptions of the scientific community may thus become a major actor in the society-profile, in relation with the public opinion and role on the economy, sociological structure, and the condition and definition of fairness, etc., of the nation.

Yet there is another problem in the Western countries, it is the recruitment of scientific advances to the benefits of only the top $1 \%$ group, with a bias against the rest $99 \%$. We see that in the food and pharmaceutical industries, in health care, and in the "planned obsolesce" behavior of many manufacturers. ${ }^{130}$ Recruitment of the technological advancements to the benefits of a certain group of the society can enslave the population. This should be dealt with and doing so is not against the technological advancement but is rather about increasing the public awareness and proper (right and just) actions involving the control issue of the technologies.

To conclude this discussion, we would like to emphasize that combining concepts of science of education and socio-econo-physics might define fairness more precisely. Such definitions can then be utilized in mathematical modeling with socio-economic perspectives, to explain the nations' stability and fairness. Such interactions and influences can increase the model accuracy and therefore might have a positive effect on the policy makers' activities. For example, public opinion surveys about the definitions in the society and the perspectives of the society's properties can help us to compute indices that appear in the fairness formula as per nation score. ${ }^{76}$ 


\subsection{Defining fairness}

The nations' socioeconomic realities can be explained with the stochastic models of the dynamics in the societies, e.g., Refs. 76-79, 86-95. With the most accurate model, we can define stability in nations and quantify the nations' resources' allocation properly. Further, we can test the free economy arguments, define fairness in the nation, ${ }^{76}$ test policies' effects on the nation, etc. The intuitive definition of fairness is probably the state that allows the achievements and success, based on the abilities and contributions, with proper evaluation. Clearly, fairness is not the priority of a certain group in the society and should include the concepts of freedom, free economy, etc. The personal drive advances personal profits, yet the contributions of the nation's structure can be computed and fairness can be advanced through e.g., the tax code and the flow of opportunities. The (socio)economic crises in the recent years showed that the nations all around the world including the Western democracies, the socialist or capitalist nations, are all lacking fairness. The basic problems are distinct from debates such as whether the government should intervene or the free economy should be implemented. In fact, even in the capitalist USA, the right winger republican regime that supports government-free economy nationalized many parts of the economy (including banks, various industries, etc.) in the wake of the economic crisis, during September 2008. Such activities persisted during the Obama regime, and strengthened with the central bank's massive purchases of bonds and assets from the private banks. These acts were duplicated worldwide. Whether this is the right move depends on the results. The results showed that in the USA, the wealth density (the percent of wealth of every socioeconomic percentile in the nation; see Fig. 3) became distorted more, and so the fairness. Government intervention should help all citizens but the analyses showed that the top percentile benefited the most from the bailout money. ${ }^{131}$ The top percentile also benefited the most from the "boosting economy activities" of the central bank since the stock exchange tripled from these bond purchase activities, where big companies profited the most, and the top percentile (owners of these companies) were thus favored considerably more. Fairness can promote competition but not distort the wealth density at the top $1 \%$ in an unjust manner. Governments can create better wealth densities. They can invest money in the citizens, and the small and intermediate companies. According to the basic notion that is presented here, democratic nation, freedom, free economy, and lower taxes on most, should be endorsed. Further, in case of direct interventions and acts, those should help all percentiles rather than the top $0.1 \%$ or the $1 \%$. Yet the problem is that most policies (of the U.S. governments and the others) support the top $1 \%$ even without bailout money and such severe economic interventions. This is the result form a recent study, ${ }^{132}$ and similar arguments appear in the work of many economists as well. ${ }^{78,79,107}$

The case of USA is described but the excessive wealth of the top $1 \%$ appears in all the Western democracies. Therefore, we argue that the reasons are universal. Accordingly, biases that favor the top $1 \%$ create structures that we see in the current 
nations. Therefore, fairness should be generated and promoted by policies that can balance the unjust interventions in favor of the top $1 \%$.

Main problems that are tackled are therefore the distorted wealth densities and the means that they are created, together with the biased flow of wealth. ${ }^{76,81,93,94,107,133}$ These are global issues as they appear in almost any nation, together with the global influences. Therefore, global effects should be in the models, besides the national policies. The solutions of the economic problems should end up by increasing the flow of opportunities and generating better wealth densities while abolishing the unjust biases. The relevant society-deciders model is reviewed in Sec. 5, the first part. This model can be used to check whether the nation is stable and if the situation would likely to be improving in favor of the society in times of crises. Modeling of the wealth density is reviewed in Sec. 5.2. It is showing the difference in the environment of the wealth groups at the top of the society and the rest. The model of the wealth density can answer questions on how to create smoother wealth densities that would result in increased fairness in nations.

\section{Fairness, Mathematical Modeling}

\subsection{Defining fairness mathematically by utilizing socio economic modeling}

\subsubsection{The society-deciders model}

The society-deciders model ${ }^{76}$ that we will describe in this section is explaining the economic and sociological stability in a nation. The model has two groups that are interconnected, the deciders and the society. The system is either stable or collapsing. If the deciders collapse due to harsh conditions in the society camp, the nation is defined as fair. That is defining fairness and is the indicator for measuring the stability in a nation and predicting the chances a change would be favoring the $99 \%$ circle in the society. Within the model, long lasting crises are solved by increasing fairness rather than interventions that increase or decrease the governmental debt.

\subsubsection{The model}

The system is based on those making the decisions, "the deciders", who interact with the masses of people, most of the society. The basic "economic" relation in the societydeciders model is similar to that in the Lotka Volterra model in ecology, which is describing the dynamics in a population of prey and predators. ${ }^{82-84}$ Accordingly, the deciders (predators) must show sensitivity to the situation of the society (prey). Otherwise they risk extinction. In the society-deciders model, the group of the deciders is at the top socio economic percentile, the top $1 \%$ of the population. In fact, it is the one in a thousand $(0.1 \%)$ group on top, yet that group belongs to the top $1 \%$. This

group includes businessmen, politicians, intellectuals, celebrities, etc., and the "clan's elders", including the retirees from these communities. The deciders' influence is observed through formal channels, e.g., high rank positions in the public sectors, 
politics, military, media, academia, companies, etc., and also through informal channels, including accumulated money, networks and family ties, fame, advanced means of communication, etc. The society-deciders model is explicitly based on the common wisdom that the deciders in the society are in fact a distinct group that controls most of the resources of the country, e.g., Refs. 78 and 79. Therefore, this model is about inequalities in accessing the nations' opportunities and the other types of inequalities, e.g., Refs. 93 and 94.

\subsubsection{The model illustration and equations}

\subsubsection{The society}

In the society-deciders model, the society is defined with the temperature, $T(t)$,

$$
T(t)=w(t)+\xi(t)
$$

wherein, $w(t)$ is the total opinion of the deciders (see the next sub-section), $\xi(t)$ is a Brownian motion with variance $c$ that stands for all the occurrences in the nation of interest and in the others that have an effect on the system that is being tested. $T$ can take any real value. When $|T(t)|$ is small, the society is stable, while it is in a crisis if $|T(t)|$ is large.

\subsubsection{The deciders}

In the society-deciders model, the deciders try to have higher influence in their camp, and keep their position, namely survive. They risk elimination if they hold an unpopular opinion for a long time. The model for the deciders is an equation of motion for $X_{\delta}(x, t)$, giving the number of deciders, who hold the opinion $\delta$ with a particular level of influence $x$ at time $t$. The $\delta$ is either plus or minus $(\delta=+,-)$. The dynamics of $X_{\delta}(x, t)$ is as follows:

$$
\begin{aligned}
\partial_{t} X_{\delta}= & \left(D \partial_{x x}+v \partial_{x}\right) X_{\delta}+k_{b, \delta} \delta(x)-\left(k_{d, \delta}(x)+f_{\delta}(x)\right) X_{\delta}-c_{\delta} X_{\delta} \tilde{X}_{-\delta} \\
& +c_{-\delta} X_{-\delta} \tilde{X}_{\delta} \\
\delta= & +,-
\end{aligned}
$$

The deciders diffuse in the influence coordinate $x\left(D \partial_{x x}\right)$, where a constant force towards the origin exists $\left(v \partial_{x}\right)$, showing that it is hard to win influence in the deciders' system. At the origin there is a reflecting boundary. Birth $\left(k_{b, \delta} \delta(x)\right)$ and death terms $\left(-k_{d, \delta}(x)\right)$ are included. Deciders join the system at the origin. The death term represents deciders' elimination. The death and the birth terms are balanced most of the time, and only in extreme conditions a net change in the number of deciders is observed. Terms for changes in the opinions are also there in Eq. (2), wherein a stress term $\left(f_{\delta}(x)\right)$ represents those that decided to start from scratch with a different opinion. A reaction represents those that decided switching groups, after encountering with deciders of at least a similar influence yet with a different opinion $\left(-c_{\delta} X_{\delta} \tilde{X}_{-\delta}\right)$. In this situation, the decider switches opinion yet 


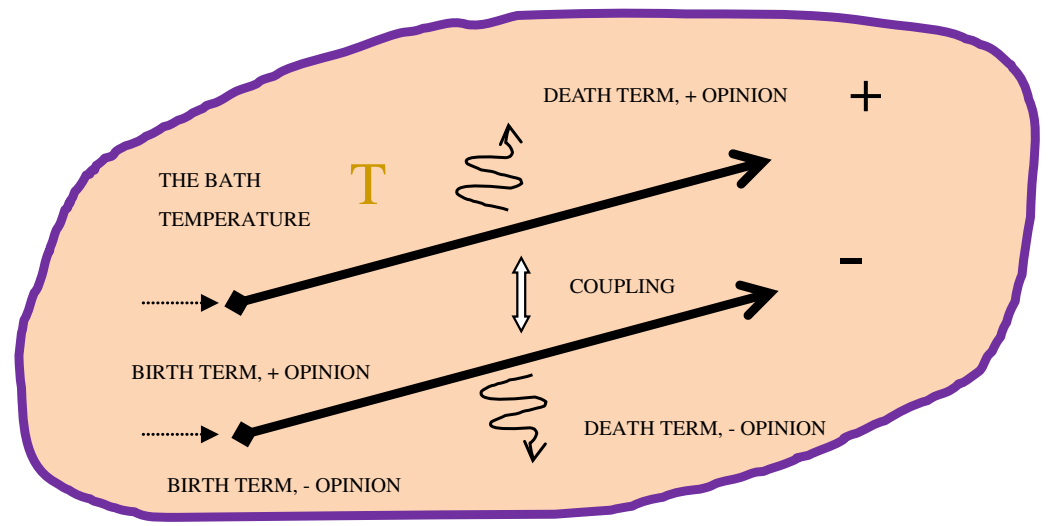

Fig. 2. Illustration of the society-deciders model. The structures representing the nation, where the bulk is the society with temperature T and the deciders' potentials' curves are represented with the inclined curves, where the arrows represent the deciders flow (either from the system (curly arrows) or between opinions or inside the system (broken dashed)).

would still be having the exact level of influence that was obtained during the previous years, in another opinion-group. All the functions that control the dynamics and survival of the deciders depend on $e^{\delta \frac{T}{T}}$, making the connection among the deciders and the people. $\tilde{T}$ is therefore the interaction strength among the society and the deciders. The index fairness is the $\tilde{T}$ relative to the optimal value. Figure 2 illustrates the process. The opinion $w$ in Eq. (1) is a simple average of the functions of $X_{ \pm}(x, t) .{ }^{76}$

\subsubsection{Results}

The results are derived by solving equations (1) and (2) numerically yet also analytically, working with the simplified version. ${ }^{76}$ Particular results about nations are derived by expressing the model coefficient with socio-economic indicators that represent the conditions per nation. ${ }^{76}$

\subsubsection{In general}

The society-deciders model showed that shifting the wealth and the control on the flow of wealth in the direction of the society, farther from the deciders is central to all approaches for solving the economic woes in (almost) any nation, instead of cutting or increasing the governmental spending. Therefore, the model is suggesting solving the profound economic problems rather than a "buying time" until the next crisis, with measures that increase fairness (checking the effect of any regulation on the stability of the deciders is therefore crucial).

Other general results; In the model, the most basic indicator in a nation is the freedom index, and only then comes the democracy index, and the local and global 
economic and political indicators follow only afterwards. The tradition in a nation influences the stability of the deciders and may cause biases favoring the deciders. Yet, education might balance that. Long lasting mass protests signal the deciders' collapse.

\subsubsection{In particular}

The fairness in the USA is smaller than that in many of the European nations and in fact, USA loses its rank relative to many other nations, in comparison to the other socio-economic indices, e.g., the democracy index. ${ }^{134}$ The reasons are the presence of more distorted wealth distribution and much higher world-wide strength, which is favoring the deciders even more, relative to those in the other nations. Therefore, changes in favor of the society are more probable in the other nations. For e.g., the money that was injected in the USA economy in 2009-2010 was accessed mainly by the top 1\% (see, e.g., "Striking it Richer: The Evolution of Top Incomes in the United States", Emmanuel Saez, a draft that appears in the website of Emmanuel Saez), and that decreased fairness. This could have influence in the next crisis.

Now, a similar trend with that of the state of fairness in USA is observed in the relatively larger European nations, such as France and UK, which are having lower states of fairness than that in most of the smaller European nations. Yet, Germany retained its relative position, with respect to the democracy index; also, South Korea, South Africa and Mexico all lost their rank and many others bypassed them. The reasons are similar to those in case of USA. Another interesting result is that India bypassed both USA and Japan, and actually has the highest fairness among all the largest 13 nations. The reason is the relative smoothness of India's wealth distribution at the top; although the poor are very poor and the $2 / 3$ of the population earns $2 \$$ a day.

When a nation shifts in the direction of freedom and democracy, its fairness increases significantly, and this induces further improvements. For example, increasing fairness also increases the opportunities. Examples include Egypt, Libya and Tunisia, these improved fairness in an order of magnitude with the recent citizens' activities and revolutions, based on improved freedom and democracy. This may sound contradictory to the current analysis on such occasions in the Middle East. ${ }^{135-137}$ However, what we mean here is that in many cases, activities such as mass protests increase the flow of opportunities and increase fairness, when those are evaluated by the authorities as the wills of the society for more freedom, and better and fairer rules and regulations rather than mere acts of the chronic opponents of the governors. So, such protests are the means to ask for fairer systems but they do not provide any guarantee for fairer systems by themselves. The suggestion here is to view and treat the citizens' approach to change and influence and reshape the power structure in the nations.

Table 2 is showing the results of 49 nations, their fairness, temperature of stability $\left(\tilde{T}_{1}\right)$, and noise coefficient $\left(c_{1}\right)$ values. We can compute each of these parameters per country, with the model and formulae of these coefficients that were developed from the derived and/or known socioeconomic indicators. ${ }^{76}$ 
Table 2. List of 49 nations with their $c_{1}, \tilde{T}_{1}$, fairness, and $c_{1} / \tilde{T}_{1}$ values taken from Ref. 76 .

\begin{tabular}{|c|c|c|c|c|}
\hline Nation & $\tilde{T}_{1}$ & fairness & $c_{1}$ & $c_{1} / \tilde{T}_{1}$ \\
\hline Bangladesh & 17.30719 & 0.15196 & 1.59445 & 0.092126 \\
\hline Belgium & 4.401868 & 0.597474 & 2.410741 & 0.547663 \\
\hline Brazil & 23.53166 & 0.111764 & 3.915307 & 0.166385 \\
\hline Canada & 3.272534 & 0.803659 & 2.503214 & 0.764916 \\
\hline China & 2855.858 & 0.000921 & 1.332551 & 0.000467 \\
\hline Denmark & 3.544228 & 0.742052 & 1.980798 & 0.55888 \\
\hline Ecuador & 23.75878 & 0.110696 & 1.867416 & 0.078599 \\
\hline Egypt & 24.0214 & 0.109486 & 2.072009 & 0.086257 \\
\hline Ethiopia & 125.3395 & 0.020983 & 2.001479 & 0.015968 \\
\hline Finland & 3.023628 & 0.869816 & 1.846181 & 0.610585 \\
\hline France & 5.808504 & 0.452784 & 2.513692 & 0.432761 \\
\hline Germany & 4.696572 & 0.559983 & 2.20296 & 0.469057 \\
\hline Ghana & 7.889523 & 0.333354 & 1.952555 & 0.247487 \\
\hline Greece & 5.136294 & 0.512042 & 4.03871 & 0.786308 \\
\hline Hungary & 4.279036 & 0.614624 & 2.1885 & 0.511447 \\
\hline India & 6.677717 & 0.393847 & 2.163482 & 0.323985 \\
\hline Indonesia & 18.28795 & 0.143811 & 1.73947 & 0.095116 \\
\hline Iran & 1330.415 & 0.001977 & 1.901241 & 0.001429 \\
\hline Iraq & 85.12792 & 0.030895 & 1.690459 & 0.019858 \\
\hline Israel & 6.342396 & 0.41467 & 2.2985 & 0.362402 \\
\hline Italy & 6.381826 & 0.412108 & 2.738017 & 0.429034 \\
\hline Japan & 9.164781 & 0.286968 & 3.493835 & 0.381224 \\
\hline Jordan & 145.6764 & 0.018054 & 1.70243 & 0.011686 \\
\hline Lebanon & 14.3396 & 0.183408 & 2.726553 & 0.190141 \\
\hline Libya & 25.05711 & 0.10496 & 2.14347 & 0.085543 \\
\hline Mali & 12.45297 & 0.211195 & 2.083469 & 0.167307 \\
\hline Mexico & 49.66331 & 0.052957 & 1.822402 & 0.036695 \\
\hline Netherlands & 3.359794 & 0.782786 & 2.111037 & 0.628323 \\
\hline New Zealand & 2.611722 & 1.006998 & 1.793982 & 0.686896 \\
\hline North Korea & 961.0246 & 0.002737 & 2.538455 & 0.002641 \\
\hline Norway & 2.539711 & 1.035551 & 2.005523 & 0.789666 \\
\hline Pakistan & 191.4577 & 0.013737 & 1.845501 & 0.009639 \\
\hline Philippines & 19.97212 & 0.131684 & 1.914864 & 0.095877 \\
\hline Poland & 4.639541 & 0.566866 & 2.206284 & 0.475539 \\
\hline Portugal & 4.80012 & 0.547903 & 2.981965 & 0.621227 \\
\hline Qatar & 299.2918 & 0.008787 & 1.813635 & 0.00606 \\
\hline Romania & 7.224267 & 0.364051 & 2.283703 & 0.316116 \\
\hline Russia & 550.3108 & 0.004779 & 1.66535 & 0.003026 \\
\hline Saudi Arabia & 1099.726 & 0.002392 & 1.511778 & 0.001375 \\
\hline South Africa & 22.42513 & 0.117279 & 2.412686 & 0.107589 \\
\hline South Korea & 5.108875 & 0.51479 & 1.564411 & 0.306214 \\
\hline Spain & 4.555415 & 0.577335 & 2.13086 & 0.467764 \\
\hline Sweden & 3.16763 & 0.830274 & 1.708957 & 0.539506 \\
\hline Switzerland & 2.633616 & 0.998627 & 1.889282 & 0.717372 \\
\hline Syria & 554.3508 & 0.004744 & 2.010758 & 0.003627 \\
\hline Tunisia & 151.3173 & 0.017381 & 2.08099 & 0.013752 \\
\hline Turkey & 30.5731 & 0.086023 & 1.850037 & 0.060512 \\
\hline United Kingdom & 6.480146 & 0.405855 & 2.314256 & 0.35713 \\
\hline United States & 12.94444 & 0.203176 & 2.434666 & 0.188086 \\
\hline
\end{tabular}




\subsection{Modeling the income density and the wealth distribution}

The density of the income $c, f(c)$ is the probability density to earn wages $c$ per month in the nation. The $f(c)$ and the income distribution, $F(c)\left(=\int^{c} f(\tilde{c}) d \tilde{c}\right)$, in addition to the society income curve, which is derived from $F(c)$, are central to explaining a nation. With freedom and democracy, these are predicting the situation of the citizens the most, and telling about the flow of opportunities in the society. The society wealth curve is also derived from $f$ and is the wealth of each fraction in the society.

The income density function $f$ is thus the basic quantity, from where we can compute various other quantities. The properties of these functions explain the nation, with the averages, fluctuations, and the Gini. ${ }^{97}$ The Gini is a number in the range between 0 and 1 . It tells how distorted the function $f$ is relative to the condition of "all are the same (type of) nation" (Gini $=0)$. The Gini of fairness is $\leq 40 \%{ }^{77}$ It means that the nation is (explicitly or implicitly) corrupt beyond that.

To create the density $f$, we should first generate and develop the model. Many models exist yet we present here the $f(c)$ structure that is based on the type that is derived from the "society-deciders" model. ${ }^{77}$ The model is showing how valuable is the strength of interactions in creating smoother $f(c)$, and resulting in better (fairer) societies.

\subsubsection{Various forms of the income density $f$}

\subsubsection{The income exponential density}

The simplest form of $f(c)$ that is observed in nations is the exponential income density, appearing in many cases to describe the poorer $90 \%$ of the population. ${ }^{96-101,138}$ The income exponential density is:

$$
f(c)=e^{-\frac{(c-\mu)}{\theta}} / \theta, \quad c \geq \mu
$$

wherein, $\mu$ is the minimal wages (see Fig. 3). The income exponential density is derived from the "fair economics' dynamics", wherein the opportunities of the people's chances of receiving rewards and benefits are based on their capabilities and efforts, see e.g., Refs. 96-101 and 138. This is equal to the $f(c)$ diffusion equation with a linear potential (see the next Eqs. (6) and (7)), telling that those with the income $c$ face potentials, proportional to their income. The maximal value of Gini is $50 \%$ there. So, the Gini $=1 / 2\left(1+\frac{\mu}{\theta}\right)$.

\subsubsection{The income Pareto density}

The Pareto density is observed in the nations' top circle and is as follows:

$$
f(c)=\left(\frac{\gamma}{\mu}\right)\left(\frac{c}{\mu}\right)^{-1-\gamma}, \quad c \geq \mu
$$

wherein, this $f(c)$ is based on biased dynamics, meaning that the "rich are getting richer" ${ }^{106}$ or it suggests logarithmic potential in the $f(c)$ diffusion equation (see the 
next Eqs. (6), (7) and (8)), which is also emphasizing the biased environment of the top percentile.

Here in Eq. (4), $\mu$ is the minimal wages, where just when $\gamma>2$, the fluctuations $(\sigma)$ are finite and we see a fair nation, where the rich are just moderately rich. The Gini there $(\gamma \rightarrow 2)$ is $33 \%$, where the maximal value of the Gini is 1 (where $\gamma \rightarrow 1$ ), and Gini $=1 /(2 \gamma-1)$.

\subsubsection{The combined case $f$}

In many cases in the world, the income density for the $90 \%$ group (or the $95 \%$ group) is the $f(c)$ with exponential shape, where only part of the society that receive the top income is having the Pareto density $f(c)$ :

$$
f(c)= \begin{cases}0 & \mu>c \\ \# \frac{1}{\theta} e^{-\frac{c-\mu}{\theta}} & \tilde{c} \geq c \geq \mu \\ \# \frac{1}{\theta} e^{-(\tilde{c}-\mu) / \theta}\left(\frac{c}{\tilde{c}}\right)^{-1-\gamma} & c \geq \tilde{c}\end{cases}
$$

where \# is the normalization.

In the case where $\gamma \approx 2$, the Gini is in the $40 \%$ area, again showing that Gini $\approx$ $40 \%$ is the transition from fairness to corruption since that is also the value where the fluctuations in the income density are finite ${ }^{77}$ (see the next Fig. 3).

\subsubsection{The combined case dynamics}

About the dynamics for the combined case;

The equation of motion for $f(c)$ can completely define and explain how the situation in the society is generated and how the society can be influenced. Various dynamics were proposed for the combined case, based on stochastic dynamics. ${ }^{96-101,138}$ From Ref. 77, we present a dynamic equation to the density with two groups, where the whole society is defined as two parts, the "society" and "deciders". SC stands for the society group and DC for the deciders. These two groups interact through the same temperature (general interactions) yet they also interact directly. The equation of motion for the income probability density e.g., to $P_{S C}(c, t)$ is:

$$
\partial_{t} P_{S C}(c, t)=\partial_{c}\left(U_{S C}^{\prime}(c) P_{S C}(c, t)\right)+D \partial_{c}^{2} P_{S C}(c, t)+\text { interactions term }
$$

The potential (up to a free constant) in the society case is:

$$
U_{S C}=(c-\mu) / \theta
$$

and in the deciders' case is:

$$
U_{D C}=(1+\gamma) \ln (c / \tilde{c})
$$

Therefore, this model shows further the problem in the society that has a distorted income density with two groups since the rich-group diffuses almost without any 


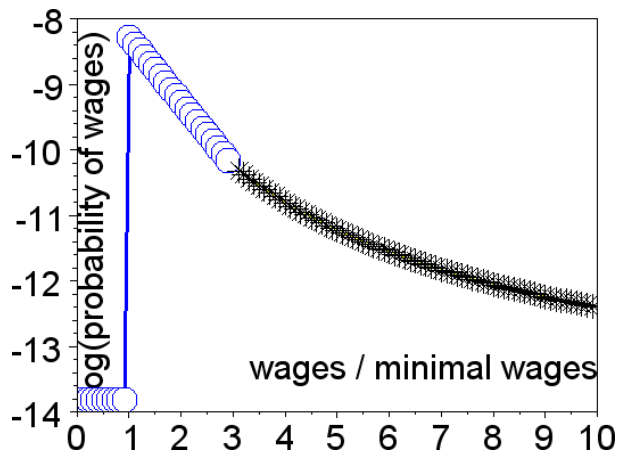

(a)

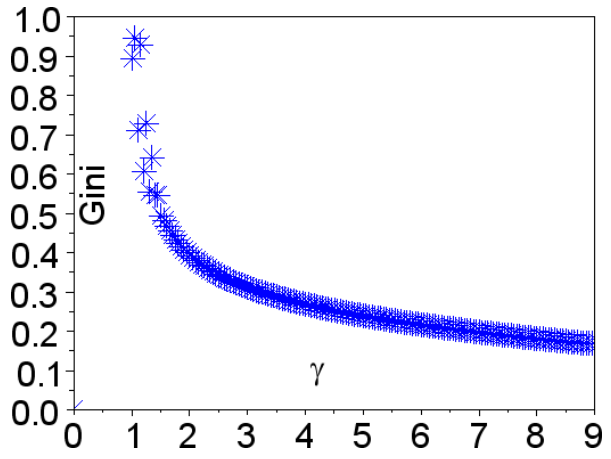

(b)

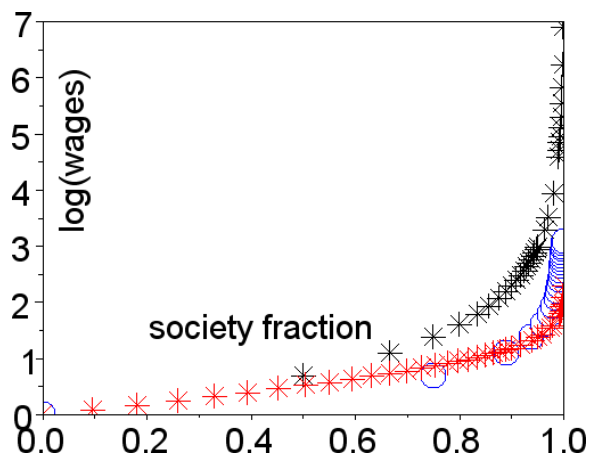

(c)

Fig. 3. (a) A log linear plot of the combined case income density function. The vertical curve is $\mu$, the light blue curve (circles) is the exponential income curve with $\theta=\mu$, and the black curve (stars) is the Pareto curve with $\gamma=1$, (b) The Gini for the combined income density function as a function of the $\gamma$, with $\theta=1.4 \mu$, where the fair Gini is where $\gamma \geq 2$, and (c) The society income curve on a log linear scale, with normalization, wages/minimal wages ( $y$ axis). This function is the income of every percentile in the society. Red curve is the exponential income curve (lower curve, stars), blue curve is Pareto income curve with $\gamma=2$ (circles) and the black curve is the Pareto income curve with $\gamma=1$ (upper curve, stars). It is clear that the top $0.1 \%$ are very rich just in the Pareto $\gamma=1$ curve, while in the other cases, each curve is continuous and the rich are just moderately rich.

opposition while the poor-group faces difficulties that increase with the income (seen from the various forms of $U$ ).

In the first approximation, $v^{0} \rightarrow 0$. Therefore, in equilibrium, $P_{S C}(c)$ and $P_{D C}(c)$ are the functions in Eq. (5) (the second and third rows, respectively). The correction term depends on the interaction's model there. In Ref. 77, the interaction's model functions yield a net flow of about $3 \%$ of $P_{S C}(c)$ in the interaction area, and that is the circle of about $5 \%$ of the society top. This result is valuable since it is showing how the interactions with the top circle can create a smoother $f$, even in a society where two camps exist. 


\subsubsection{Gini of fairness}

Through utilizing methods from the socio-econo-physics, we reviewed the results that involve the Gini of fairness in a democratic and free nation, where fairness is income distribution's Gini values that satisfy Gini $<40 \%$. Possible activities to create a fair society includes the activities of the citizens to replace the "top $0.1 \%$ money" e.g., by crowd funding, implementing special taxation on the top $0.1 \%$ (also relative to the $20 \%$ poor situation), fighting corruption and monopolies that build the biased economy that favors the top $1 \%$, and establishing interactions with the top circle (the top third with the deciders). It is worth to elaborate the last statement further. The model showed that creating another circle of socio economic fraction just in between the top camp and the society that can interact with the top will create smoother $f$. This result is important and its relevant suggestion differs from the others since they just recommend fighting the top $0.1 \%$. Clearly, the upper circle tends to concentrate the control on the wealth there, and therefore interactions can be created only when the control on the flow of wealth is moved from the top to the others. This is possible when the citizens organize and get together to create citizensbased/managed-organizations, e.g., such financial institutes.

\section{Conclusion}

This review focused on the strength of socio-econo-physics, and the other areas, in explaining nations, resulting from the diversity of approaches and the unbiased starting point. Various distinct subjects were mentioned, including the historical review of biophysical economics on the energetic balances, ecological issues, and a section was dedicated to the views of the society on the scientific advances and how the nations are affected by those. Then, discussions on the scope of the socio-econophysics and the impact of these approaches in the scientific community and the nations followed. Beyond these, a core sociological concept, fairness, was defined with a mathematical model (the society-deciders model) that is based on structuring the nation as two circles, the top group (deciders) and the rest (society). This model and approach is relevant to the work on modeling opinion formation as well, e.g., Ref. 139.

The model of the wealth density was also presented here. It was revealing the inequality between the wealth distributions, in line with the concept that dissects the nation into the deciders and the society groups. It may seem strange to dissect the society into two major groups but the aim here was to somehow represent the dramatic inequality in the population percentiles' strength of these two groups, the sizes of which are inversely proportional with the wealth distribution. The Gini of fairness was also discussed in this review and finally, other than just suggesting the reinforcement of freedom and democracy, regulations that advance the flow of wealth to the society group are offered in order to increase fairness. Interactions are important, and are part of the means to affect the closed, isolated systems. In this sense, 
establishing interactions with the "deciders" that form the top percentile group by means of citizens-sourced-organizations was recommended.

Here we commonly termed fairness basically as the receipt of benefits and rewards, based on relative efforts and capabilities and contributions, with proper evaluation, and by considering the nationwide regional biases that could be due to geographic, economic, political, or other constraints. Yet, while making such definitions, it is always assumed that the conditions in question and applications are not contradicting the basal expectations like the good practices of the Human Rights since those are not limited by income or status. Finally, here we discussed models and every model has the potential to be valid if it is correct (representative enough) and the underlying assumptions are satisfied. The reader is to evaluate this review accordingly, and we realize the fact that the work presented here is only a minor portion of the current literature and ongoing efforts. Yet, we focused in this work on various subjects, where recent complementary approaches are indeed presented in the other projects of the Special Issue, e.g., Refs. 140 and 141.

\section{References}

1. François Quesnay, "Tableau économique" (Economic Table, 1758).

2. A. Smith, The Theory of Moral Sentiments (Edinburgh, 1759).

3. Biemer and Lyberg, Introduction to Survey Quality (John Wiley \& Sons, US, 2003).

4. D. R. Samson et al., Evol. Anthropol. 24 (2015) 225.

5. T. F. Neil, Quarterly Journal of Economics 63 (1949) 532.

6. P. Weinberger, Philosophical Magazine 93 (2013) 2576.

7. G. Lebon, D. Jou and J. Casas-Vázquez, Understanding Non-Equilibrium Thermodynamics (Springer, Heidelberg, 2008), p. 113.

8. S. Carnot, Réflexions sur la puissance motrice du feu et sur les machines propres à développer cette puissance (Bachelier, Paris, 1824). S. Carnot, H. Carnot, V. T. B. Kelvin, Reflections on the Motive Power of Heat and on Machines Fitted to Develop that Power, edited and translated by R. H. Thurston (Wiley, New York, 1890; Macmillan, London, 1890).

9. H. Spencer, First Principles (Appleton, New York, 1880).

10. S. Podolinsky, Die Neue Zeit 1, March-April (1883).

11. W. Ostwald, Monist 17 (1907) 480.

12. J. S. Steinhart and C. E. Steinhart, Science 184 (1974) 307.

13. D. Pimentel and M. Pimentel, Food, Energy and Society (Edward Arnold Ltd., London, 1979), p. 165.

14. C. J. Cleveland, Agriculture, Ecosystems, and the Environment 55 (1995) 111.

15. C. J. Cleveland, R. Costanza, C. A. S. Hall and R. Kaufmann, Science 255 (1984) 890.

16. W. F. Cottrell, Energy and Society (McGraw-Hill, New York, 1955), p. 330.

17. H. T. Odum, Environment, Power and Society (Wiley-Interscience, New York, 1971), p. 330 .

18. M. W. Gilliand, Science 189 (1975) 1051.

19. C. A. S. Hall, C. J. Cleveland and R. K. Kaufmann, Energy and Resource Quality: The Ecology of Economic Process (Wiley Interscience, New York, 1986).

20. F. Soddy, Cartesian Economics (Hendersons, London, 1922).

21. F. Soddy, Wealth, Virtual Wealth, and Debt (E. P. Dutton, New York, 1926).

22. A. J. Lotka, Washington Academy of Sciences 4 (1914) 409. 
23. A. J. Lotka, Proceedings of the National Academy of Sciences 8 (1922) 147.

24. E. R. Berndt, From Technocracy to Net Energy Analysis: Engineers, Economists and Recurring Energy Theories of Value, in Progress in Natural Resource Economics, eds. A. Scott (Clarendon, Oxford, 1983), pp. 337-366.

25. L. A. White, The Science of Culture (Farrar-Straus, New York, 1949).

26. L. A. White, The Evolution of Culture (McGraw-Hill, New York, 1959).

27. E. Ayres and C. Scarlott, Energy Sources - The Wealth of the World (McGraw-Hill, New York, 1952).

28. P. C. Putnam, Energy in the Future (Van Nostrand, New York, 1953).

29. M. K. Hubbert, Nuclear energy and the fossil fuels, in Drilling and Production Practice (American Petroleum Institute, New York, 1956).

30. H. Thirring, Energy for Man (Harper, New York, 1958).

31. M. K. Hubbert, Science 109 (1949) 103.

32. M. K. Hubbert, Energy Resources. A Report on the Committee on Natural Resources (National Academy of Sciences, Government Printing Office, Washington D. C., 1962), Publication No. 1000-D.

33. M. K. Hubbert, American Association of Petroleum Geologists Bulletin 51 (1967) 2207.

34. M. K. Hubbert, Man's conquest of energy: Its ecological and human implications, in Future Environments of North America, eds. F. F. Darling and J. P. Milton (Natural History Press, Garden City, New York, 1966).

35. R. Costanza, Science 210 (1980) 1219.

36. R. Costanza, Embodied energy, energy analysis, and economics, in Energy, Economics and the Environment: Conflicting Views of an Essential Interrelationship, eds. H. E. Daly and A. Umana (American Association for the Advancement of Science - AAAS Selected Symposium Series, Westview Press, Boulder Co, 1981).

37. E. F. Cook, Science 191 (1976) 676.

38. E. F. Cook, Man, Energy, Society (Freeman, San Francisco, 1976), p. 478.

39. B. Hannon, Science 189 (1975) 95.

40. B. Hannon, Energy, growth and altruism, in Alternatives to Growth, eds. D. L. Meadows (Ballinger, Cambridge, 1977), pp. 79-100.

41. R. U. Ayres, Resources, Environment, and Economics: Applications of the Materials/ Energy Balance Principle (John Wiley and Sons, New York, 1978).

42. R. Ayres and I. Nair, Physics Today 35 (1984) 62.

43. R. Ayres and A. Kneese, American Economic Review 59 (1969) 282.

44. R. Ayres, L. W. Ayres and K. Martiñas, Eco-Thermodynamics: Exergy and Life Cycle Analysis (INSEAD, Center for the Management of Environmental Resources, France, 1996), Working Paper 96/04.

45. H. E. Daly, Review of Social Economy 43 (1985) 279.

46. H. E. Daly, Steady-State Economics (W. H. Freeman, San Francisco, 1977).

47. N. Georgescu-Roegen, Bioscience 27 (1977) 266.

48. N. Georgescu-Roegen, Comments on the Papers by Daly and Stiglitz, in Scarcity and Growth Reconsidered, eds. V. K. Smith (Johns Hopkins University Press, Baltimore, 1979), pp. 95-105.

49. N. Georgescu-Roegen, Energy, matter, and economic valuation: Where do we stand, in Energy, Economics and the Environment: Conflicting Views of an Essential Interrelationship, eds. H. E. Daly and A. F. Umana (American Association for the Advancement of Science, 1981).

50. B. Fix, Rethinking Economic Growth Theory from a Biophysical Perspective (SpringerVerlag, Berlin, Heidelberg, 2015), pp. 107-115.

51. J. Robinson, The Review of Economic Studies 21 (1953) 81. 
52. J. Robinson, Economic Philosophy (Aldine Pub. Co., Chicago, 1962).

53. N. Georgescu-Roegen, The Entropy Law and the Economic Process (Harvard University Press, Cambridge, Massachussets, 1971).

54. W. Leontief, American Economic Review 61 (1971) 1.

55. P. Mirowski, More Heat Than Light: Economics as Social Physics, Physics as Nature's Economics (Cambridge University Press, Cambridge, 1989).

56. C. Hall, D. Lindenberger, R. Kümmel, T. Kroeger and W. Eichhorn, BioScience 51 (2001) 663.

57. C. Hall and K. Klitgaard, Energy and the Wealth of Nations: Understanding the Biophysical Economy (Springer, New York, 2012).

58. S. Keen, Debunking Economics: The Naked Emperor of the Social Sciences (Zed Books, New York, 2001).

59. J. Nitzan and S. Bichler, Capital as Power: A Study of Order and Creorder (Routledge, New York, 2009).

60. P. S. Dasgupta and G. M. Heal, Economic Theory and Exhaustible Resources (Cambridge University Press, Oxford, 1979).

61. N. Meshkov and R. S. Berry, Can thermodynamics say anything about the economics of production, in Changing Energy Use Futures, eds. R. A. Fazzolare and C. B. Smith (Pergamon Press, New York, 1979), pp. 374-382.

62. C. Perrings, Economy and Environment: A Theoretical Assay on the Interdepedence of Economic Environmental Systems (Cambridge University Press, Cambridge, 1987).

63. M. Ruth, Ecological Economics 13 (1995) 99.

64. P. Christensen, Ecological Economics 1 (1989) 17.

65. U. Bardi and A. Lavacchi, Energies 2 (2009) 646.

66. L. Szilard, Zeitschrift für Physik 53 (1929) 840.

67. D. T. Spreng, Energy Policy 21 (1993) 13.

68. X. Chen, ENER Bulletin 12 (1992) 45.

69. X. Chen, Energy Policy 22 (1994) 15.

70. M. Ruth and C. W. Bullard, Energy Policy 21 (1993) 1059.

71. Y. Veneris, Environ. Plan. A 22 (1990) 399.

72. E. J. Wilson, The Information Revolution and Developing Countries (MIT Press, US, UK, 2004).

73. C. W. London, Who were the physiocrats?, The Economist Oct 11th 2013, (2013). Accessed on 10.08.2016, web-site: http://www.economist.com/blogs/freeexchange/ 2013/10/economic-history-0

74. M. Weber, The nature of the city, in Classic Essays on the Culture of Cities, ed. R. Sennett (Prentice-Hall Inc., Englewood Cliffs, New Jersey, 1969).

75. 10 Things You Need to Know About Sanitation, prepared by WHO in cooperation with UNICEF and WSSCC, http://www.unwater.org/wwd08/docs/10Things.pdf.

76. O. Flomenbom, Biophys. Rev. Lett. 10 (2015) 157.

77. O. Flomenbom et al., The Gini of Fairness, This issue.

78. Here, the reader is encouraged seeing articles appearing in the media from familiar economists about the structure of $1 \%$ and $99 \%$ : P Krugman We are the $99.9 \%$ in NY Times (2011), and J E Stiglitz Of the 1\%, by the 1\%, for the 1\% in Vanity Fair (2011).

79. G. W. Domhoff, Who Rules America? Challenges to Corporate and Class Dominance (McGraw-Hill Humanities, N.Y., 2009).

80. D. Colander, M. Goldberg, A. Haas, K. Juselius, A. Kirman, T. Lux and B. Sloth, Cri. Rev. 21 (2009) 249.

81. D. Acemoglu and J. Robinson, Why Nations Fail: The Origins of Power, Prosperity, and Poverty (Profile Books Ltd, London, Great Britain, 2012). 
82. A. J. Lotka, J. Phys. Chem. 14 (1909) 271.

83. A. J. Lotka, Elements of Physical Biology (Williams and Wilkins, Baltimore, Maryland, USA, 1925).

84. V. Volterra, Variations and fluctuations in the number of individuals in animal species living together, in Animal Ecology, eds. R. N. Chapman (McGraw-Hill, New York, 1931).

85. S. Vijaya and E. Rekha, Bio. Phys. Rev. Letts. 11(2) (2016) 1750001.

86. V. M. Yakovenko and J. Barkley Rosser Jr, Rev. Mod. Phys. 81 (2009) 1703.

87. E. Kussell and S. Leibler, Science 309 (2005) 2075-2078.

88. S. Galam, Phys. Rev. E 71 (2005) 046123.

89. C. Nardini, B. Kozma and A. Barrat, Phys. Rev. Lett. 100 (2008) 158701.

90. X. Guardiola, A. Díaz-Guilera, C. J. Pérez, A. Arenas and M. Llas, Phys. Rev. E 66 (2002) 026121.

91. W. Dong, B. Lepri and A. Pentland, Modeling the Co-evolution of Behaviors and Social Relationships using Mobile Phone Data, The international conference on mobile and ubiquitous multimedia. Beijing, China (2011).

92. Y. Kim, B. Han and S.-H. Yook, Phys. Rev. E 82 (2010) 046110.

93. M. Fleurbaey and F. Maniquet, A Theory of Fairness and Social Welfare (Cambridge University Press, NY, USA, 2011).

94. D. Herzer and S. Vollmer, J. Econ. Inequal. 10 (2012) 489.

95. A. Pentdal, http://socialphysics.media.mit.edu/papers (2015).

96. D. G. Champernowne, The Distribution of Income between Persons (Cambridge University Press, 1973).

97. C. Gini, Concentration and Dependency Ratios (in Italian, 1909), English translation in: Rivista di Politica Economica 87 (1997) 769.

98. K. Xu, How has the Literature on Gini'S Index Evolved in the Past 80 Years? Economics working paper, Dalhousie University, http://ssrn.com/abstract=423200 or doi:10.2139/ ssrn.423200 (2003).

99. S.-B. Kang and Y.-S. Cho, Korean Journal of Computational \& Applied Mathematics 5 (1998) 213.

100. F. Clementi and M. Gallegati, Physica A 330 (2005) 427.

101. A. C. Silva and V. M. Yakovenko, Europhysics Letters 69 (2005) 304, arXiv:cond-mat/ 0406385 .

102. Y. Tao, Universal Laws of Human Society's Income Distribution, http://arXiv.org/abs/ 1506.05418 .

103. J.-P. Bouchaud and M. Mézard, Physica A 282 (2000) 536.

104. K. H. Ho, F. K. Chow and H. F. Chau, Phys. Rev. E 70 (2004) 066110.

105. A. Chatterjee and P. Sen, Phys. Rev. E 82 (2010) 056117.

106. A. Chakraborti, D. Challet, A. Chatterjee, M. Marsili, Y.-C. Zhang and B. K. Chakrabarti, Phys. Rep. 552 (2015), arXiv:1305.2121.

107. T. Piketty, Capital in the Twenty-First Century (The Belknap Press of Harvard University Press, Cambridge, Massachusetts London, England, 2014).

108. J. Sienkiewicz and J. A. Hołyst, Phys. Rev. E 80 (2009) 036103.

109. D. Lamper, S. D. Howison and N. F. Johnson, Phys. Rev. Lett. 88 (2002) 017902.

110. S. Fortunato and C. Castellano, Phys. Rev. Lett. 99 (2007) 138701.

111. C. M. Bordogna and E. V. Albano, Phys. Rev. E 76 (2007) 061125.

112. A. Chatterjee, M. Mitrović and S. Fortunato, Scientific Reports 3 (2013) 1049.

113. A. M. Calvão, N. Crokidakis and C. Anteneodo, PloS ONE 10 (2015) e0137732.

114. R. Lemoy, E. Bertin and P. Jensen, EPL 93 (2011) 38002.

115. A. Arenas, A. Díaz-Guilera, C. J. Pérez and F. Vega-Redondo, Phys. Rev. E61 (2000) 3466. 
116. Y. Tao, Phys. Rev. E 82 (2010) 036118.

117. J. Tenenbaum, D. Horvatić, S. C. Bajić, B. Pehlivanović, B. Podobnik and H. E. Stanley, Phys. Rev. E 82 (2010) 046104.

118. Y. Tao and X. Chen, Chin. Phys. Lett. 29 (2012) 058901.

119. C. J. Cleveland, Biophysical economics from physiocracy to ecological economics and industrial ecology, in Advances in Bioeconomics and Sustainability: Essay in Honor of Nicholas Gerogescu-Roegen, eds. J. Gowdy and K. Mayumi (Edward Elgar Publishing, Cheltenham, England, 1999), pp. 125-154.

120. Y. Adigüzel, Historical and critical review on biophysical economics, Bio. Phys. Rev. Letts. 11(2) (2016) 1630001.

121. M. Dale, S. Krumdieck and P. Bodger, Ecological Economics 73 (2012) 152.

122. M. Dale, S. Krumdieck and P. Bodger, Ecological Economics 73 (2012) 158.

123. Biemer and Lyberg, Introduction to Survey Quality (John Wiley \& Sons, US, 2003).

124. J. R. Fraenkel and N. E. Wallen, How to Design and Evaluate Research in Education, 3rd edn. (Mcgraw-Hill, 1996).

125. T. S. Kuhn, The Structure of Scientific Revolutions (The University of Chicago Press, Chicago, 1962).

126. B. Latour and S. Woolgar, Laboratory Life - The Constructions of Scientific Facts (Princeton University Press, Princeton, NJ, US, 1986).

127. M. Foucault, The Order of Things - An Archeology of Human Sciences (Routledge, NY, US, 1970).

128. G. S. Aikenhead, What is STS science teaching, in STS Education: International Perspectives in Reform, eds. J. Solomon and G. Aikenhead (Teacher's College Press, New York, 1994).

129. G. Thomas and J. Durant, Why should we promote the public understanding of science, in Scientific Literacy Papers, ed. M. Shortland (Oxford University Department for External Studies, Oxford, 1987), pp. 1-14.

130. https://vimeo.com/162337948

131. See, "Striking it Richer: The Evolution of Top Incomes in the United States", Emmanuel Saez, a draft that appears in the website of Emmanuel Saez, https://eml.berkeley.edu/ $\sim$ saez/saez-UStopincomes-2013.pdf.

132. M. Gilens and B. I. Page, Testing theories of American politics: Elites, interest groups, and average citizens, Perspectives on Politics, in press (2014).

133. E. Guillaud, J. Econ. Inequal. 11 (2013) 57.

134. L. Kekic, The Economist Intelligence Unit's index of democracy, The World in 2007, http://www.economist.com/media/pdf/DEMOCRACY_INDEX_2007_v3.pdf.

135. F. Chau, R. Deesomsak and J. Wang, Int. Fin. Markets, Inst. and Money 28 (2014) 1.

136. D. A. Downs, Civil liberties and human rights, in International Encyclopedia of the Social \&3 Behavioral Sciences, 2nd ed., Vol. 3 (Elsevier, 2015), pp. 674-679. Doi:10.1016/ B978-0-08-097086-8.86008-0

137. H. Lehkonen and K. Heimonen, Journal of International Money and Finance 59 (2015) 77.

138. T. S. K. Moothathu, Sankhyāa, Series B 47 (1985) 247.

139. S. Biswas, A. K. Chandra, A. Chatterjee and B. Chakrabarti, J. Phys.: Conf. Ser. 297 (2011) 012004.

140. Nuno Crokidakis et al., this issue.

141. The Introduction, this issue. 